geometrical problem than that of $\S 4$, viz., where the triangle instead of being equilateral has two sides equal and enclosing a definite angle. We must now know which of the three given distances is the one drawn to the meeting point of the equal sides of the triangle; and taking this distance we make it one of the equal sides of an isosceles triangle similar to that specified, and on the third side describe a triangle with its two other sides equal to the remaining two given distances, and as before join the vertices not common to the two triangles. *

\title{
Bishopton, Glasgow,
}

26th Dec. 1884.

\section{Geometrical Notes.}

By J. S. Magkay, M.A.

I. A straight line $\mathbf{K} \mathbf{K}^{\prime}$ meets the circumference of a circle at two real or two imaginary points $K, K^{\prime}$, and $H$ is the middle point of the real or imaginary chord $K K^{\prime}$. If $A, B, C, D$ be any four points on the circumference, and the pairs of straight lines $A B, D C, A C, B D$, $A D, C B$ rneet $K^{\prime} K^{\prime}$ at the pairs of points $E, E^{\prime}, F, F^{\prime}, G, G^{\prime}$; then if any one pair of points be equidistant from $H$, the two other pairs will also be equidistant.

To prove that $\mathbf{E}, \mathbf{E}^{\prime}$ are equidistant from $\mathbf{H}$, if $F, F^{\prime}$ are.

First Demonstration. (Figures 14, 15.)

Through A draw $\mathbf{A A}^{\prime}$ parallel to $\mathrm{KK}^{\prime}$; join $\mathrm{A}^{\prime} \mathrm{E}^{\prime}, \mathrm{A}^{\prime} \mathrm{F}^{\prime}$, and since $E^{\prime}, F^{\prime \prime}$ are on $D C, D B$, join $A^{\prime} D$.

Then $\mathrm{AFF}^{\prime} \mathrm{A}^{\prime}$ may be proved to be a convex or crossed isosceles and therefore cyclic trapezium, having $A^{\prime} F^{\prime}=A F$, and angle $A^{\prime} F^{\prime} E^{\prime}$ $=$ angle $\mathrm{AFE}$.

- Professor Chrystal pointed out that a particular case of this, viz,, where the triangle is isosceles right-angled is dealt with in the Annals of Mathematics, I., p. 24, and Mr Fraser has since received from Dr Rennet, of Aberdeen, a reference to Thomas Simpson's Algebra, 2nd edition, (1755) p. 369, where a very general problem of this nature is stated and solved. 
Now angle $A^{\prime} A O$ is supplementary to angle $A^{\prime} D C$, and angle $A^{\prime} A C$ is equal to angle $A^{\prime} \mathbf{F}^{\prime} \mathbf{E}^{\prime}$; therefore angle $A^{\prime} F^{\prime} E^{\prime}$ is supplementary to angle $A^{\prime} D C$; therefore the points $A^{\prime}, F^{\prime}, E^{\prime}, D$ are concyclic ; therefore angle $\mathrm{F}^{\prime} \mathrm{A}^{\prime} \mathrm{E}^{\prime}$ = angle $\mathrm{F}^{\prime} \mathrm{DE} \mathrm{E}^{\prime}$,

$$
\text { = angle } \mathrm{FAE} \text {. }
$$

Hence triangles $A^{\prime} E^{\prime} F^{\prime}$ and $\triangle E F$ are congruent, and $E^{\prime} F^{\prime}=E F$, and consequently $\mathrm{HE}^{\prime}=\mathrm{HE}$.

'The proof that $G, G^{\prime}$ are equidistant from $H$, if $F, F^{\prime}$ are, is similar to the preceding.

\section{Second Demonstration. (Figures 14, 15.)}

Let $\mathrm{AC}, \mathrm{BD}$, on which are $\mathrm{F}, \mathrm{F}^{\prime}$, meet at $\mathrm{L}$.

Consider the triangle $\mathrm{LFF}^{\prime}$ as cut by the transversals $\mathrm{AB}, \mathrm{CD}$, which determine the points $E, E^{\prime}$.

We obtain $\quad \mathbf{L A} \cdot \mathbf{F E} \cdot \mathrm{F}^{\prime} \mathbf{B}=\mathbf{F A} \cdot \mathrm{F}^{\prime} \mathrm{E} \cdot \mathrm{LB}$, and $\quad \mathrm{LC} \cdot \mathbf{F E} \cdot \mathbf{F}^{\prime} \mathrm{D}=\mathbf{F C} \cdot \mathbf{F}^{\prime} \mathrm{E}^{\prime} \cdot \mathrm{LD}$;

therefore, by multiplication and noting that $L A \cdot L C=L B \cdot L D$, we have $\mathrm{FE} \cdot \mathrm{FE}^{\prime} \cdot \mathrm{F}^{\prime \prime} \mathrm{B} \cdot \mathrm{F}^{\prime} \mathrm{D}=\mathrm{FA} \cdot \mathrm{FC} \cdot \mathrm{F}^{\prime} \mathrm{E} \cdot \mathrm{F}^{\prime} \mathrm{E}^{\prime}$.

Now $F^{\prime} B \cdot F^{\prime} D=F^{\prime} K \cdot w^{\prime} K^{\prime}=F K^{\prime} \cdot F K=F A \cdot F C$;

therefore $\quad \mathrm{FE} \cdot \mathrm{FE}^{\prime}=\mathrm{F}^{\prime} \mathrm{E} \cdot \mathrm{F}^{\prime} \mathrm{E}^{\prime}$;

therefore $\quad F E: F^{\prime} E=F^{\prime} E^{\prime}: F^{\prime}$;

therefore $\quad F E: F^{\prime}=F^{\prime} E^{\prime}: F F^{\prime}$.

Hence $\mathrm{FE}=\mathrm{F}^{\prime} \mathrm{E}^{\prime}$, and consequently $\mathrm{HE}=\mathrm{HE}^{\prime}$.

It may be proved that $\mathbf{F E} \cdot \mathbf{F E}^{\prime}=\mathbf{F}^{\prime} \mathbf{E} \cdot \mathbf{F}^{\prime} \mathbf{E}^{\prime}$, without introducing the segments $F K, F K, F^{\prime} K, F^{\prime} K^{\prime}$, which in figure 15 are inaginary, in the following way :-

Because $\quad \mathrm{FE} \cdot \mathrm{FE}^{\prime} \cdot \mathrm{F}^{\prime} \mathrm{B} \cdot \mathrm{F}^{\prime} \mathrm{D}=\mathrm{FA} \cdot \mathrm{FC} \cdot \mathrm{F}^{\prime} \mathrm{E} \cdot \mathbf{F}^{\prime} \mathrm{E}^{\prime}$, therefore $\quad F E \cdot F E^{\prime}: F^{\prime} E \cdot F^{\prime} E^{\prime}=F A \cdot F C: F^{\prime} B \cdot F^{\prime} D$, $= \pm\left(r^{2}-O F^{2}\right): \pm\left(r^{2}-O F^{2}\right)$,

where $r$ denotes the radius of the circle, and the upper sign is to be taken in figure 14, the lower sign in figure 15.

Now $O F=O F^{\prime}$, since $F, F^{\prime}$ are equidistant from $H$;

therefore $\quad \mathbf{F E} \cdot \mathbf{F E} \mathbf{E}^{\prime}=\mathbf{F}^{\prime} \mathbf{E} \cdot \mathbf{F}^{\prime} \mathbf{E}^{\prime}$.

Third Demonstration. (Figure 14.)

Join BK, BK', CK, CK'.

Since the pairs of angles subtended at $\mathrm{B}$ and $\mathrm{C}$ by the arcs $\mathrm{KA}$, $\mathrm{AD}, \mathrm{DK}^{\prime}$ are equal ; 
therefore the pencils $\mathrm{B} \cdot \mathrm{KADK}$ and $\mathrm{C} \cdot \mathrm{KADK}$ are superposable; therefore the anharmonic ratio of $B \cdot K A D K '$ is equal to the anharmonic ratio of $\mathrm{C} \cdot \mathrm{KADK}$,

that is, $\quad \mathbf{K} \mathbf{K}^{\prime} \cdot \mathbf{E F ^ { \prime }}: \mathbf{K E} \cdot \mathbf{F}^{\prime} \mathbf{K}^{\prime}=\mathbf{K} \mathbf{K}^{\prime} \cdot \mathbf{F E}^{\prime}: \mathbf{K F} \cdot \mathbf{E}^{\prime} \mathbf{K}^{\prime}$.

Now since $\mathrm{F}^{\prime} \mathrm{K}^{\prime}=\mathrm{KF}$, this proportion becomes

$\mathbf{E F}^{\prime}: \mathbf{K E}=\mathbf{F E}^{\prime}: \mathbf{E}^{\prime} \mathbf{K}^{\prime}$;

therefore

$\mathbf{E F}^{\prime}: \mathbf{F}^{\prime} \mathbf{K}=\mathrm{FE}^{\prime}: \mathrm{FK}^{\prime}$.

But $\mathbf{F}^{\prime} \mathbf{K}=\mathbf{F K}^{\prime}$; therefore $\mathbf{E F}^{\prime}=\mathbf{F E}^{\prime}$.

Hence $E$ and $E^{\prime}$ are equidistant from $F$ and $F^{\prime}$, and consequently from $\mathrm{H}$.

The theorem to which $\mathrm{Mr}$ James Taylor called attention last session (see Proceedings of the Edinburgh Mathematical Society for $1883-4$, p. 4) is easily seen to be a particular case of the foregoing.

II. Between two sides of a triangle to inflect a straight line which shall have given ratios to the segments of the sides between it and the base.

Let $\mathrm{ABC}$ be the triangle, and let $p: q$ and $r: q$ be the ratios of the segments of the sides to the inflected straight line.

\section{First Method. (Figure 16.)}

From $\mathrm{BA}$ cut off $\mathrm{BD}=p$; through $\mathrm{D}$ draw $\mathrm{DE}$ parallel to $\mathrm{BC}$. Cut off $\mathrm{OF}^{\prime}=r$; with centre $\mathrm{F}^{\prime}$ and radius $=q$, cut $\mathrm{DE}$ or $\mathrm{DE}$ produced at the points $G^{\prime}$; and join $F^{\prime} G^{\prime}$. Let $C^{\prime}$ meet $A B$ or $A B$ produced at $G$, and draw GF parallel to $G^{\prime} F^{\prime}$. GF is the line required.

For through $G^{\prime}$ draw $G^{\prime} B^{\prime}$ parallel to GB.

Then $\mathrm{B}^{\prime} \mathrm{G}^{\prime}=\mathrm{BD}=p$.

Now, since the quadrilaterals $\mathrm{CB}^{\prime} \mathrm{G}^{\prime} \mathrm{F}^{\prime}, \mathrm{CBGF}$ are similar, and either similarly or oppositely situated, $O$ being their centre of similitude; and since $\mathrm{B}^{\prime} \mathrm{G}^{\prime}: \mathrm{G}^{\prime} \mathrm{F}^{\prime}: \mathrm{F}^{\prime} \mathrm{C}=p: q: r$;

therefore $\mathrm{BG}: \mathrm{GF}: \mathrm{FC}=p: q: r$.

\section{Second Method. (Figure 17.)}

Take $\mathrm{BD}$ such that $\mathrm{AC}: \mathrm{BD}=r: p$; and through $\mathrm{D}$ draw $\mathrm{DE}$ parallel to $B C$. With centre $A$ and radius $A G^{\prime}$, such that $A C: A^{\prime}$ $=r: q$, cut $\mathrm{DE}$ or $\mathrm{DE}$ produced at the points $\mathrm{G}^{\prime}$; and join $\mathrm{AG}^{\prime}$. Let $\mathrm{CG}^{\prime}$ meet $\mathrm{AB}$ or $\mathrm{AB}$ produced at $\mathrm{G}$, and draw $\mathrm{GF}$ parallel to $G^{\prime} A . \quad G F^{\prime}$ is the line required. 
For through $G^{\prime}$ draw $G^{\prime} B^{\prime}$ parallel to $G B$.

Then $\mathrm{B}^{\prime} \mathrm{G}^{\prime}=\mathrm{BD}$; therefore $\mathrm{AC}: \mathrm{B}^{\prime} \mathrm{G}^{\prime}=r: p$.

Now since the quadrilaterals $C^{\prime} G^{\prime} A, C B G F$ are similar, and either similarly or oppositely situated, $\mathrm{C}$ being their centre of similitude; and since $\mathrm{B}^{\prime} \mathrm{G}^{\prime}: \mathrm{G}^{\prime} \mathrm{A}: \mathrm{AC}=p: q: r$;

therefore $\mathrm{BG}: \mathbf{G F}: \mathbf{F C}=p: q: r$.

\section{Third Method. (Figure 18.)}

Take $\mathrm{AD}^{\prime}$ such that $\mathrm{AO}: \mathrm{AD}^{\prime}=r: p$. With centre $\mathrm{D}^{\prime}$ and radius $\mathrm{D}^{\prime} \mathrm{B}^{\prime}$, such that $\mathrm{AC}: \mathrm{D}^{\prime} \mathrm{B}^{\prime}=r: q$, cut $\mathrm{BO}$ or $\mathrm{BC}$ produced at the points $\mathrm{B}^{\prime}$; and join $\mathrm{D}^{\prime} \mathrm{B}^{\prime}, \mathrm{D}^{\prime} \mathrm{C}$. Through $\mathrm{B}$ draw $\mathrm{BD}$ parallel to $\mathrm{B}^{\prime} \mathrm{D}^{\prime}$ to meet $\mathrm{CD}^{\prime}$ or $\mathrm{CD}^{\prime}$ produced at $\mathrm{D}$; through $\mathrm{D}$ draw $\mathrm{DF}$ parallel to $A B$ to meet $A C$ or $A O$ produced at $F$; and through $F$ draw $\mathrm{FG}$ parallel to $\mathrm{BD}$ to meet $\mathrm{AB}$ or $\mathrm{AB}$ produced at $\mathrm{G}$. $\mathrm{GF}$ is the line required.

For $\mathrm{BG}=\mathrm{DF}$, and $\mathrm{GF}=\mathrm{BD}$.

Now since the quadrilaterals $C^{\prime} D^{\prime} A, C B D F$ are similar and either similarly or oppositely situated, $O$ being their centre of similitude; and since $\mathrm{AD}^{\prime}: \mathrm{D}^{\prime} \mathrm{B}: \mathrm{AC}=\boldsymbol{p}: q: \boldsymbol{r}$;

therefore $\mathrm{FD}: \mathrm{DB}: \mathrm{FC}=p: q: r$;

therefore $\mathrm{BG}: \mathrm{GF}: \mathrm{FC}=p: q: r$;

With these three methods, which are essentially the same, it may be interesting to compare Proceedings of the Edinburgh Mathematical Society for 1883-4, p. 27 ; Educational Times, vol. 37, p. 328; Vuibert's Journal de Mathématiques Elémentaires, $9^{\circ}$ année, p. 45.

The following solution of the problem, in the case when $p, q, r$ are equal, is due to Mr Robert John Dallas.

(Figure 19.)

Suppose the thing done.

Then since $\mathrm{BD}=\mathrm{ED}, \angle \mathrm{ADE}=2 \angle \mathrm{DBE}$.

Similarly $\angle \mathrm{AED}=2 \angle \mathrm{ECD}$.

Now $\angle A D E+\angle A E D=\angle A B O+\angle A C B$;

therefore $\angle \mathrm{DBE}+\angle \mathrm{ECD}=\frac{1}{2}(\angle \mathrm{ABC}+\angle \mathrm{ACB})$;

therefore $\angle \mathrm{OBC}+\angle \mathrm{OCB}=\frac{1}{2}(\angle \mathrm{ABO}+\angle \mathrm{ACB})$,

$=\mathbf{a}$ constant angle;

therefore $O$ lies on the circumference of a known circle.

If $O$ could be found on this circumference, so that $B D$ might be equal to $\mathrm{CE}$, the problem would be solved ; for in proving $\mathrm{O}$ to lie on this circumference it was assumed that $\mathrm{BD}=\mathrm{DE}$. 
Draw CF parallel to $\mathrm{AB}$. Take any point $\mathrm{G}$ in $\mathrm{AC}$, make $\mathrm{CH}=$ CG, and join GH cutting $\mathrm{BC}$ in $\mathrm{K}$.

On GH describe a segment of a circle containing an angle equel to $\frac{1}{2}(\angle A B C+\angle A C B)$, and let the are of the segment cut $B C$ at $R$. Through $B$ draw BE parallel to $R G$, and BF parallel to $R H$.

Then by similar triangles it will follow that $\mathbf{E C}=\mathrm{FC}$, and $\angle \mathrm{EBF}=\angle \mathrm{GRH}=\frac{1}{2}(\angle \mathrm{ABC}+\angle \mathrm{ACB})$.

Let $\mathrm{BE}$ meet at $\mathrm{O}$ the arc of the segment described on $\mathrm{BC}$, and containing an angle equal to the supplement of $\frac{1}{2}(\angle A B C+\angle A C B)$.

Then $\angle \mathrm{EOC}=\frac{1}{2}(\angle \mathrm{ABC}+\angle \mathbf{A C B})=\angle \mathrm{EBF}$;

therefore $\mathrm{BDCF}$ is a parallelogram, and $\mathrm{BD}=\mathrm{FC}$.

Now EC has been proved equal to $\mathrm{FC}$, and $\mathrm{O}$ is on the circumference of the known circle;

therefore $\mathrm{BD}=\mathrm{DE}=\mathrm{EC}$.

Fourth Meeting, February 13th, 1885.

A. J. G. Barclay, Esq., M.A., President, in the Chair.

Not'e on a Plane Strain.

By Professor Tart.

The object of this note is to point out, by a few remarks on a single case, how well worth the attention of younger mathematicians is the full study of certain problems, suggested by physics, but limited (so far as that science is concerned) by properties of matter.

In de St Venant's beautiful investigations of the flexure of prisms, there occurs a plane strain involving the displacements

$$
\xi=\frac{x y}{\mathrm{D}}, \eta=\frac{y^{2}-x^{2}}{2 \mathrm{D}} \text {. }
$$

Physically, this is applicable to de St Venant's problem only when $x$ and $y$ are each small compared with $D$. But it is interesting to consider the results of extending it to all values of the cöordinates. This I shall do, but very briefly. 